\title{
Correction: Metformin limits osteoarthritis development and progression through activation of AMPK signalling
}

Li J, Zhang B, Liu W, et al. Metformin limits osteoarthritis development and progression through activation of AMPK signalling. Ann of Rheum Dis 2020;79:635-45. doi:10.1136/ annrheumdis-2019-216713.

The following funding information was missed from the final version:

This work was supported by the National Institutes of Health (NIH) Grant R01AR070222 to DC. This work was also partially supported by grants from the National Nature Science Foundation of China (NSFC) (81620108018, 81930070), and Tianjin key research and development plan, key projects for science and technology support (19YFZCSY00660) to SF. This work was also partially supported by NSFC grants $(81874011,81572104$ and 81301531) to TW. This work was also supported by the NSFC grant (81672227) and the Frontier Science of CAS grant (QYZDB-SSW-JSC030) to HP.

(C) Author(s) (or their employer(s)) 2020. No commercial re-use. See rights and permissions. Published by BMJ.

Ann Rheum Dis 2020;79:e119. doi:10.1136/annrheumdis-2019-216713corr1

D Check for updates 